\title{
Evaluation of Dental Students' Satisfaction With the Quality of Virtual Education in Alborz Dental School During COVID-19 Pandemic
}

Homa Zare

Alborz University of Medical Sciences

Masomeh Esmaily ( $\square$ M.esmaily@abzums.ac.ir)

Alborz University of Medical Sciences

manijeh mohammadian

Alborz University of Medical Sciences

\section{Research Article}

Keywords: Dental students, Virtual education, Cross-sectional studies, COVID-19

Posted Date: March 3rd, 2022

DOI: https://doi.org/10.21203/rs.3.rs-1354776/v1

License: (c) (i) This work is licensed under a Creative Commons Attribution 4.0 International License.

Read Full License 


\section{Abstract}

Background: With the beginning of COVID-19 pandemic and daily increases in the number of new cases, there have been significant changes in people's lifestyle and needs, and members of society have faced various challenges. Closure of schools and universities with the purpose of preventing further spread of the disease has turned preparation and implementation of educational programs for continuity in home education during lockdown the biggest challenge for educational systems.

Methods and materials: This was a cross-sectional study conducted among dental students of Alborz University of medical sciences. In this research, the questionnaire was designed as 5-option multiplechoice questions that evaluated participants' satisfaction with virtual education, personal computers and internet access, and got their opinions on the efficiency of virtual education in dental education and university's limitations.

Results: Satisfaction with the efficiency of virtual courses, preferring traditional education to virtual teaching and inclination to a combination of traditional and virtual education was more than moderate, while it was less than moderate concerning teachers' responsiveness and evaluation methods. Furthermore, students were highly satisfied with their access to virtual facilities, and moderately satisfied with the amount of presented content and expected duties. The overall level of student satisfaction was assessed as moderate and males were more inclined towards virtual education than females. However, their age and place of residence had no significant impact on their satisfaction levels.

Conclusion: Students' satisfaction level with the quality of virtual education in Alborz dental school is moderate. Students are inclined to combining education methods. Participants' sex and year of entry significantly affected their satisfaction levels, whereas there was no significant relationship observed between their age or place of residence and the level of satisfaction.

\section{Background}

Since the COVID-19 outbreak in 2020 and with its pandemic all over the country and daily increases in the number of new cases, there have been great changes in people's lifestyle and needs, and members of the society have faced several challenges. Similarly, students have not been immune to changes and difficulties, and they are the most impacted group with regards to education and academic programs. Closure of schools and universities with the purpose of preventing the further spread of the disease has turned preparation and implementation of educational programs for continuity in home education during lockdown into the biggest challenge for educational systems. This challenge has been imposed to all countries including ours. International structures and organizations like WHO and UNICEF were forced to prepare academic programs and educational and training guidelines for this new situation. One of the important and serious programs that was proposed and implemented by higher education organizations was education through cyberspace [1]. In fact, virtual education is a great opportunity to face the 
limitations of in-person education, make real the dream of education for all and plan consistent and balanced development of the country[2].

In-class education has been the most common method of learning and education for many years. In this method, students are expected to attend classes at certain times and in specific places, and receive faceto-face education mostly through verbal communication [3]. Nowadays, due to the developments of science and technology, constant need to learn and reeducate because of increasing expectations, limitations of resources compared to population growth, increasing demand for educational opportunities and most importantly, COVID-19 pandemic, attending in-person classes is not an option [3]. When people choose online education, they will no longer need in-person classes. They can receive all of the academic contents individually and independently of time and place either online through multimedia files uploaded on institutes' websites or offline through provided educational multimedia CDs[4].

Developments in information and communication technology, further access to computers in higher education, the need for economic activities to access new financial sources, and applications of information technology in the presentation of educational services in the global market has forced universities to revise their old methods and create new organizational structures [5]. E-learning is one of the advancements of technology in educational areas[6]. The process of education which includes teaching and learning is the result of 3 elements: teacher, student and content [7]. In order to elevate the quality of education, it needs to be formed based on people's learning methods [8]. Furthermore, there must be a chance for learners to be able to gain personal skills, manage their motivations and search and integrate information for problem solving. For this purpose, state-of-the-art technology must be used to improve and develop executive programs and gain the desirable results [9].

Cyberspace educational methods was reported by UNESCO as the most effective teaching-learning method in 2005. The experiences gained in this area are very useful. Higher education can no longer continue educating with previous models, and it needs to give priority to structural and digital changes. In a state of crisis like COVID-19 pandemic in Iran and all over the world and with the long-term closure of the universities, the need for implementing virtual education is felt more than before. Considering the problems imposed to global educational systems, virtual education growth and its opportunities for students and teachers, the best educational method is virtual education [1].

Due to its efficiency in educating with lower expenses, its availability in all places and times and elimination of traditional education's problems (e.g. the need for classes and faculties), virtual education has become an invaluable element of education. In addition, virtual education can meet people's expectations which is one of the most important reasons behind educational and learning success in all different methods [10]. This is because it is considered as a type of individual education and learners can achieve their academic goals based on their individual talents. In this method, teachers and learners are physically apart, but they stay connected with the help of products of technology [11]. Essentially, virtual education means transferring information to students through technologies like internet and communicational networks like internet and cellphones. Virtual education is a combination of 
demonstrative and vocal elements that can present the contents and tests related to an educational system, facilitate access to topic-related information and create an interactive environment [12].

Benefiting from the developments in information and communication technology, virtual education is one of the novel solutions to expand educational equity in the contemporary world. According to the experts of information and communication technology, cyberspace-based virtual education will become the common educational method. IT-based education gives students the opportunity to think innovatively and share these ideas[4]. From a medical training perspective, due to the increased number of students, lack of communication between students and teachers, large educational courses and difficulties of teaching students that are condensed in a class, new alternative methods must be taken into account. Virtual education can be used as a method of medical training either alone or in a blended educational environment [12].

Focusing on student satisfaction enables the universities to detect students' needs and adapt accordingly. A constant supervision system can be designed to evaluate efficiency in fulfilling students' needs. Therefore, a perspective based on student satisfaction is crucial for developing culture and improving the quality of education [13]. During the COVID-19 pandemic, the instructors and training staff were required to adapt quickly to the online and available training system to present courses, exams, and other required teaching and learning activities. While the sudden transition to online teaching was a necessary and mandatory action for ensuring the continuity of learning during the COVID-19 pandemic, but it was never an easy and simple process and it created many challenges for instructors, students, and their parents $[14,15]$. Student's mental health, lack of motivation, difficulty in adaptability to online learning methods, technical and bandwidth problems, and creating appropriate educational content for training courses were among the main challenges of online training[16]. Other challenges include the economic impact on families and high demands for IT training and support[17].

Online learning has changed the dental education trend in this pandemic condition. Undoubtedly, the necessity of having creativity in using available technologies, types of instructors' training, and internet access are among the most important challenges of virtual training[18].

The role of instructors is also very important in the successful adoption of educational technologies. Time, effort, and the necessities for gaining IT skills are some of the concerns of instructors related to online training. Universities should contribute to the efforts of faculty members in e-learning by holding training courses on the use of online tools[19].

In order to constantly improve educational programs, teaching and facilities, it is necessary to evaluate teachers and students' satisfaction with higher educational services. A study was conducted by Salimi et al. in 2020 to evaluate the role of corona virus in virtual education with an emphasis on opportunities and challenges. Based on the results, challenges and opportunities were classified into three levels: macro, medium and micro. At the macro level, the challenges of lack of strategic thinking among managers and planners, poor policy-making, poor educational technology, and inefficient management were met. At the medium level, the challenges of the weakness of the introduced technologies, the lack of independence 
and freedom of action, and the disruption of the budget proposed in micro level were achieved. In addition, from the participants' perspective, the impact of the corona virus has provided opportunities at the macro level (providing context for change, attention to strategic planning, and attention to online and virtual education), medium level (creating equal educational opportunity and creation of new educational innovations) and micro level. According to the results of the study, providing academic programs by combining in-class and electronic education are the most effective educational methods [1].

Rezai et al. published a study in 2020 on evaluation of students' learnings during COVID-19 pandemic with an emphasis on equal and fair evaluation. In order to gather data from other sources, the opinions of bachelor's, master's and PhD students were used through sampling and open questionnaire. Results showed that the most important evaluation methods during corona pandemic (virtual education) are inperson exams (if authorized by related principles), written virtual exam, oral virtual exam, oral questionand-answer sessions, virtual presentations, electronic cartable and multiple (integrative) evaluation. According to respondents' opinions, contenting yourself to one method discredits the evaluation. Therefore, it is necessary to use multiple (integrative) methods[20]. In 2019, Khatoon et al. conducted a study to understand the challenges, opportunities and attitudes that both dental students and tutors experience when using electronic learning. Both groups reported active use of mobile learning applications. However, students need training and further guidance when searching for, evaluating and generating evidence-based information online. Likewise, tutors need to become familiar with e-learning tools so that they may better support their students. According to this study, participants need training workshops to ensure that students are not only accessing evidence-based information, but can differentiate between evidence-based and non-evidence-based applications. The tutors in this study require information on how to provide their students with advice on using mobile technology. Institutions involved with dental training take such challenges into account [21]. In 2021, in a review article, D'Souza et al. argued different aspects of the e-learning process that must be considered before implementing and also strengths and weaknesses of online training during the COVID-19 pandemic and stated the necessary measures to increase the efficiency of e-learning in the future. Among these cases, we can mention the implementation of e-learning at all levels of the university with the latest equipment and technologies and the promotion of the scientific and practical level of students and staff in the use of elearning methods[22].

In 2020, Sarwar et al. researched to evaluate the effectiveness of virtual training during the COVID-19 pandemic in Pakistan national universities. The main purpose of this study was to determine the effectiveness of online courses. This study was conducted in a cross-sectional way using an online survey. The participants of the study were asked about access to resources and the effectiveness of online education. The results of the current study showed that the dental students of Pakistan had dissatisfaction with the various elements of the online teaching sessions. The findings of this research help the academic intuitions to create skillful learning platforms by concentrating on the improvement of students' training experiences[23]. 
In 2021, Vivek et al. used a modified questionnaire to investigate the understanding and preparation of students regarding the online training system during the COVID-19 pandemic in a descriptive and qualitative study conducted in Dehli. This study showed that students had a positive perspective on virtual training and they accepted this type of training as a new training system[24]. However, in contrast to the Viok study, qualitative research was conducted by Samra et al. in 2021 showing that undergraduate dental students have a different perspective on e-learning. However, the students were optimistic about the increased participation in online learning of their future curriculum[25].

The aim of this study was to evaluate the level of student satisfaction with virtual education in Alborz dental school during COVID-19 pandemic.

\section{Method}

This was a cross-sectional study conducted among students of Alborz dental school in the spring semester 2020-2021. In this study, students' level of satisfaction was evaluated, and for this purpose, an online researcher-made questionnaire was used. The population studied consisted of all dental students who had entered Alborz dental school between 2015 and 2019. Sample size was calculated using Cochran formula. In this formula, the size of statistical population is known (284 students of Alborz dental school). Due to the small population size, the aforementioned formula was used, and in order to

achieve the biggest sample size, $p=0.5$ was considered. According to this formula, the sample size is 163 students of Alborz dental school. The questionnaire was sent to student groups and after follow-ups through reminders, sampling was stopped when the number of filled questionnaires reached the sample size. The first part of the questionnaire included demographic questions like age, sex and year of entry. The questionnaire was designed as 5-option multiple choice questions that evaluate participants' satisfaction with virtual education, personal computer and internet access and get their opinion on the efficiency of virtual teaching in dental education and university's limitations.

The online questionnaire was designed using Porsline website. The questionnaire consists of three parts. The first part is related to students' demographic information. The second part includes questions about students' satisfaction with virtual education in Alborz dental school. The third part was about students' general opinion on virtual university classes.

Questions were 5-option multiple choice questions ranking from "extremely satisfied" to "extremely dissatisfied" for the second part, and rating from "strongly agree" to "strongly disagree" for the third part.

\section{Questionnaire's reliability and validity}

In order to assess questionnaire's validity, the self-made questionnaire including 27 questions was presented to 5 related professors. As for the questions' necessity, the CVR parameter was calculated. The CVI parameter was calculated to evaluate the simplicity, clarity and relevance of the questions. Both parameters were computed below the standard for 3 questions. Asking the professors for their opinion on the questions, the first designed questionnaire was transformed into an index questionnaire with 23 
questions. Next, the mentioned questionnaire was pilot tested by 15 students. Cronbach's alpha test was used to evaluate the reliability of the questionnaire. The reliability was confirmed as it was calculated 0.805 .

The collected data were analyzed with SPSS 21. Descriptive statistics, T-test and Chi-square test were used. A threshold probability value of ' $p \leq 0.05$ ' was employed.

\section{Results}

This is a descriptive-analytical cross-sectional study evaluating the level of Alborz dental students' satisfaction with the quality of virtual education during COVID-19 pandemic in the academic year 20202021. This study analyzed its data using SPSS 24 software.

Relative frequency distribution of sex and age among studied students of Alborz dental school were shown in Figs. 1 and 2, respectively. Participants of the study consisted of 72 males (44.2\%) and 91 females (55. 8\%). Furthermore, $95.1 \%$ of the students participating in the study lived in cities, whereas $4.9 \%$ of them resided in villages.

The largest age group was 21-24-year-olds that consisted $51.5 \%$ of the participants. The youngest and oldest participants were 18 and 35 years old, respectively. Students' mean age and standard deviation was $23.2 \pm 2.8$.

The most participants (22.7\%) had entered the university in 2017, while the smallest number of participant (16\%) had entered in 2018. According to the results, students' satisfaction level with program planning and arrangements, tutor's skill in using internet, tutor's supervision over student's learning and the possibility of making suggestions to improve the system was lower than moderate. However, their satisfaction with internet access and internet speed for participating in virtual education was evaluated as more than moderate (Since the 5-point Likert scale was used, a score of 3 out of 5 was considered as moderate). As seen in the Fig. 3, the overall students' satisfaction was evaluated as $25.8 \%$ satisfied and $22.1 \%$ dissatisfied. Mean satisfaction and standard deviation of satisfaction were calculated $3 \pm 0.7$. Through one-sample t-test and comparing it with the score of $3, p=0.88$ was obtained which shows no statistical significance.

$58.9 \%$ of the participants agreed that virtual education is effective, while $22 \%$ disagreed. The mean and standard deviation were $3.43 \pm 1.1$. According to one-sample t-test and comparing it with the score of $3, p$ $=0.00$ was obtained which shows a significant statistical difference compared to the mean.

Furthermore, while $50.4 \%$ of the students preferred traditional education, $33.8 \%$ of them were opposed to it. As mean and standard deviation were $3.29 \pm 1.1$, and $P=0.07$ was obtained, it can be deduced that the difference is statistically significant.

The results indicate that $54.6 \%$ of the students regard virtual learning as a pleasant experience and are willing to re-experience it, whereas $21.5 \%$ of them disagreed with this statement. The mean and standard 
deviation were $3.45 \pm 1.12$. Through one-sample t-test and comparing it with the score of $3, p=0.00$ was obtained which shows a significant statistical difference compared to the mean.

It can be seen from the results that the percentage of students in favor of combining traditional and online methods and those opposed to it is $76.7 \%$ and $13.5 \%$, respectively. One-sample t-test showed $p=$ 0.00 which indicates a significant statistical difference.

Tables 1 and 2 show the comparing mean level of students' satisfaction with virtual education among various sex and age groups, respectively.

It can be deduced that according to the independent t-test and the $P<0.05$, there is a significant relationship between the level of satisfaction and student sex. The calculated mean and standard deviation indicate higher level of satisfaction with virtual education among male students.

Table 2 portrays no significant association between the level of satisfaction and student age. This was concluded through ANOVA test which computed $p>0.05$.

According to the results of analysis of variance the amount of P-value was calculated less than 0.05 . It was then concluded that there was a significant association between level of satisfaction and student's year of entry.

Students who had entered university in 2016 and 2018 expressed the highest satisfaction levels. Tukey test showed a significant difference between the satisfaction of those entered in 2016 and those entered in 2017.

Table 1

Comparing mean level of students' satisfaction with virtual education among various sex groups

\begin{tabular}{|llll|}
\hline P-value & Standard deviation & Mean (score) & Sex \\
\hline 0.014 & 0.55 & 3.15 & Male \\
\cline { 2 - 4 } & 0.79 & 2.89 & female \\
\hline
\end{tabular}

Table 2

Comparing mean level of students' satisfaction with virtual education among various age groups

\begin{tabular}{|llll|}
\hline P-value & Standard deviation & Mean (score) & Age \\
\hline 0.014 & 0.54 & 3.01 & 21 and younger \\
\cline { 2 - 4 } & 0.75 & 3.01 & $21-24$ \\
\hline 0.72 & 2.99 & 25 and older \\
\hline
\end{tabular}




\section{Discussion}

Due to the importance of achievements and constant inexpensive improvements of the system, virtual education is rapidly developing, training and transforming. Nowadays, knowledge and technology are on the same path. Therefore, easily achieving one of them without the other one is not possible. Cyberspace provides users with extensive resources and facilities to gain knowledge. Furthermore, by being interactive and independent of time and place, it gives users a variety of chances with regards to their education. Virtual education is a kind of active and smart learning that while transforming the process of teaching, learning and management of knowledge, has a critical role in the cultural settling of ICT[4]. The aim of this study was to evaluate the level of student satisfaction with virtual education in Alborz dental school during COVID-19 pandemic. Regarding satisfaction with tutors' responsiveness, it should be mentioned that tutors are closely in touch with students, and they are one of the key factors in the virtual educational systems. In fact, tutor is considered a facilitator of the virtual education system. Tutors' attitude and performance can impact students' behavioral patterns, such that a tutor's negative attitude towards implementing IT tools or virtual education system can negatively affect student's attitude. Students may face problems and difficulties in their academic activities and need their tutors' assistance. Responsiveness is one of the key elements. Otarkhani[4] proved its impact on student's satisfaction with virtual education. They realized that by carefully choosing tutors and proper education, we can help virtual education systems succeed. In this study, students rated the speed and quality of tutor's responsiveness. Students' answers indicated tutors' weak responsiveness (both in terms of speed and quality) and as a result, it was concluded that students' satisfaction with tutors' responsiveness was inadequate. Likewise, the study conducted by Otarkhani showed moderate satisfaction with tutors' responsiveness. In a study done by Ghorbankhani et al.[2] Lack of connection with tutors is similarly pointed out by all the participants as a reason for dissatisfaction.

Students showed a fair level of satisfaction with the effectiveness of online classes. A study by Yasini and Taban showed that the overall effectiveness of virtual education classes was evaluated as desirable by tutors. Students believed the content of courses, slides design and workload to be favorable. However, they assessed teaching-learning activities and tutors' assistance as undesirable, and feedbacks and courses flexibility as moderately desirable. In general, students were unsatisfied with the effectiveness of courses which is inconsistent with the results of our study.

In our study, participants preferred traditional education methods to virtual education. This is consistent with a study by Weber et al.[26] which compared the effectiveness of a Web-based course delivery system to a traditional course delivery system. They found out that although a web-based course had lower scores than traditional courses, it is as effective as traditional classroom environment.

Participants thought of virtual education as a desirable experience and were willing to re-experience it. They were mostly inclined to blended education methods (in-class and online). In the study that Delavar and Ghorbani[27] did on the Role of Virtual training on the students creative learning in Universities of Bojnourd, they concluded that blended computer-based learning (online and face-to-face) has the most 
effective role in creative learning. Similarly, the results of a study by Baig et al[28]. showed that combining online and in-class education can be a proper educational strategy for dental students. A study by Dalmoline et al.[19] concluded that due to the active and sophisticated nature of learning and student's different learning styles, blended education is a great educational method and combining electronic education leads to significant improvements. It was also deduced from the Weber study that blended courses are effective in increasing students' output, and it can create an ideal balance of comfort and interaction.

\section{Conclusion}

Students of Alborz dental school were moderately satisfied with the quality of virtual education. They were inclined to combining educational methods (in-person and online). Students' level of satisfaction was significantly associated with their sex and year of entry. In contrast, satisfaction levels were not significantly related to student age and place of residence. According to the results, we are still not fully prepared to use virtual education methods alone. Actions must be taken to employ this type of education in Alborz dental school by laying the proper groundwork, providing academic, cultural and technological infrastructures and supervising and revising methods.

\section{Declarations}

\section{Acknowledgements}

The authors would like to thank the clinical research development unit of dental school, Alborz University of Medical Sciences, for technical supporting. We thank all dental students who taked time to complete the questionnaire and participated in this study.

\section{Authors' contributions}

$\mathrm{HZ}$ designed, analyzed and contributed in collecting the data, interpreting the results, and writing the draft manuscript. ME and MM contributed in guiding research design and revising the manuscript. All authors read and approved the final manuscript.

\section{Funding}

None.

\section{Availability of data and materials}

The datasets used and/or analysed in this study are in Persian and are available from the corresponding author on reasonable request but will require translation to English.

\section{Ethics approval and consent to participate}


The study was approved by the ethics committee of Alborz University of Medical Sciences with the ethics approval code 1399.289.REC.ABZUMS.IR . Participation was voluntary, anonymity was guaranteed. No individual data were collected and informed consent was obtained. All experiments and methods were carried out in accordance with relevant guidelines and regulations.

\section{Consent for publication}

Not applicable.

\section{Competing interests}

We declare no competing interests.

\section{References}

1. Salimi S, Fardin MA. The Role of Corona Virus In Virtual Education, with an Emphasis on Opportunities and Challenges. Research in School and Virtual Learning. 2020;8(2):49-60.

2. Ghorbankhani $S$, Keywan. representing the Challenges of virtual education in the Iranian Higher Education System: APhenomenological study. . quarterly journal of information and communication technology in educational sciences. 2017.

3. Pakseresht S, Khalili-Sabet M, Vahedi M, et al. Comparative study for knowledge and attitudes of virtual and non-virtual students towards e-learning. Research in Medical Education. 2016;8(4):61-68.

4. Ali A VD. measuring students satisfaction with E-learning systems. business management perspective. 2012 (10):53-78.

5. Martinez-Argüelles M, Castan J, Juan A. How do students measure service quality in e-Learning? A case study regarding an internet-based university. Electronic Journal of e-Learning Volume. 2010 01/02;8:151-160.

6. Sarboland K-A. evaluation of the effective of E-learning method in creating satisfaction among student of Islamic Azad Univercity of Northwest Iran. technology and education. 2018.

7. Oliver M. An introduction to the Evaluation of Learning Technology. Educational Technology \& Society - ETS. 2000 10/01;3.

8. Chen S. A cognitive model for non-linear learning in hypermedia programmes. British Journal of Educational Technology. 2002 09/01;33.

9. Ford N, Wood F, Walsh C. COGNITIVE STYLES AND SEARCHING. Online and CD-Rom Review. 1994;18(2):79-86.

10. Linjawi Al, Alfadda LS. Students' perception, attitudes, and readiness toward online learning in dental education in Saudi Arabia: a cohort study. Adv Med Educ Pract. 2018;9:855-863.

11. Jafari H, Azmoude E, Ahour M. Studying the knowledge and attitude of students of Torbat Heydariyeh University of Medical Sciences toward e-learning [Research]. Journal of Torbat Heydariyeh University of Medical Sciences. 2018;6(2):38-47. 
12. Sezer B. Faculty of medicine students' attitudes towards electronic learning and their opinion for an example of distance learning application. Computers in Human Behavior. 2016;55:932-939.

13. Hagen-Jurkowitsch S, Vignali C, Kaufmann H. A Student Satisfaction Model for Austrian Higher Education Providers Considering Aspects of Marketing Communications. Innovative Marketing. 2006 09/01;2.

14. Daniel J. Education and the COVID-19 pandemic. Prospects. 2020;49(1):91-96.

15. Ferrel MN, Ryan JJ. The impact of COVID-19 on medical education. Cureus. 2020;12(3).

16. Sahu P. Closure of universities due to coronavirus disease 2019 (COVID-19): impact on education and mental health of students and academic staff. Cureus. 2020;12(4).

17. Qandil AM, Abdel-Halim H. Distance e-learning is closer than everybody thought: a pharmacy education perspective. Health Professions Education. 2020;6(3):301.

18. Mathivanan SK, Jayagopal P, Ahmed S, et al. Adoption of e-learning during lockdown in India. International Journal of System Assurance Engineering and Management. 2021:1-10.

19. DALMOLIN AC, MACKEIVICZ GAO, POCHAPSKI MT, et al. Learning styles preferences and e-learning experience of undergraduate dental students. Revista de Odontologia da UNESP. 2018;47:175-182.

20. Rezaei ME. Evaluation what students have learned during the Corona: challenges and solutions. quarterly journal of educational psychology. 2020.

21. Khatoon B, Hill K, Walmsley AD. Mobile learning in dentistry: challenges and opportunities. British Dental Journal. 2019 2019/08/01;227(4):298-304.

22. Dsouza TS, Hegde MN, Pais KP. e-Learning: An Uphill to Reshaping Learning in Dentistry in India in the COVID-19 Pandemic Era. Journal of Health and Allied Sciences NU. 2021.

23. Sarwar H, Akhtar H, Naeem MM, et al. Self-reported effectiveness of e-Learning classes during COVID-19 pandemic: A nation-wide survey of Pakistani undergraduate dentistry students. European journal of dentistry. 2020.

24. Khan MA, Nabi MK, Khojah M, et al. Students' perception towards e-learning during COVID-19 pandemic in India: An empirical study. Sustainability. 2021;13(1):57.

25. Samra RK, Nirola A, Verma A, et al. Dental students' Perception on the impact of E-learning in continuing dental education during the current pandemic scenario. Indian Journal of Dental Sciences. 2021;13(2):61.

26. Weber JM, Lennon R. Multi-course comparison of traditional versus Web-based course delivery systems. Journal of educators online. 2007;4(2):n2.

27. Delavar S, Ghorbani M. The role of virtual training on the students creative learning in universities of Bojnourd, northeast Iran. Interdisciplinary Journal of Virtual Learning in Medical Sciences. 2011;2(3):17-27.

28. Baig QA, Zaidi SJA, Alam BF. Perceptions of dental faculty and students of E-learning and its application in a public sector Dental College in Karachi, Pakistan. JPMA. 2019. 
Figures

SEX

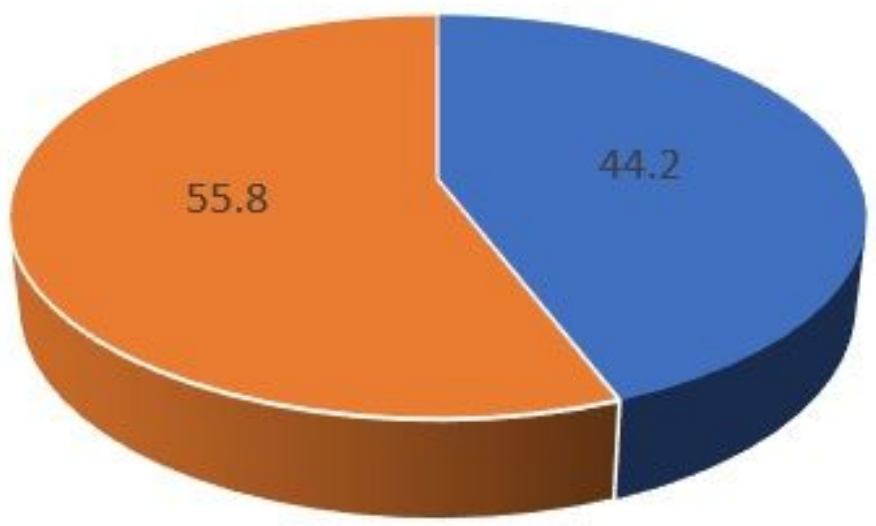

MALE - FEMALE

\section{Figure 1}

Relative frequency distribution of sex among studied students of Alborz dental school

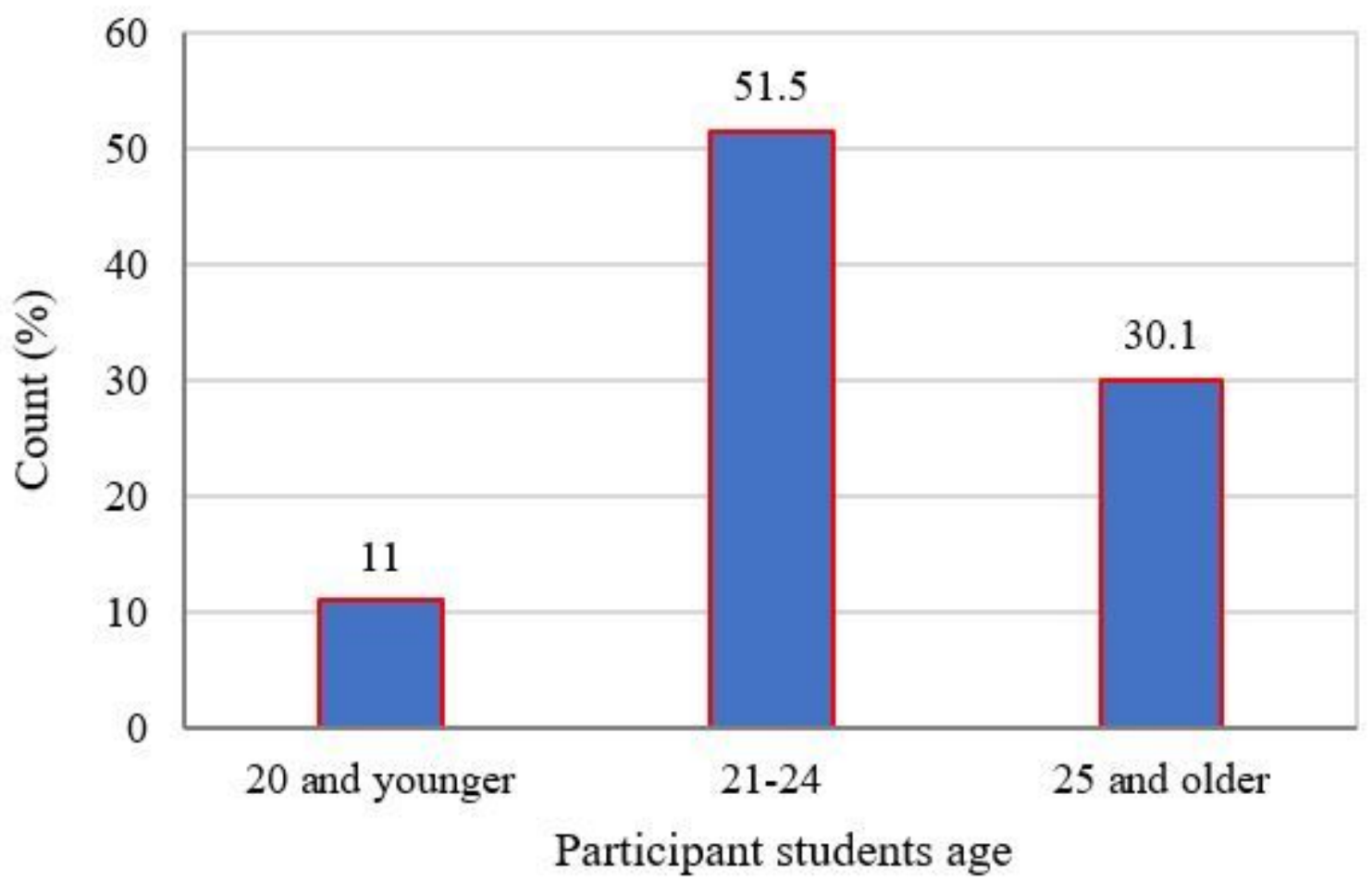

Figure 2 
Relative frequency distribution of age among studied students of Alborz dental school

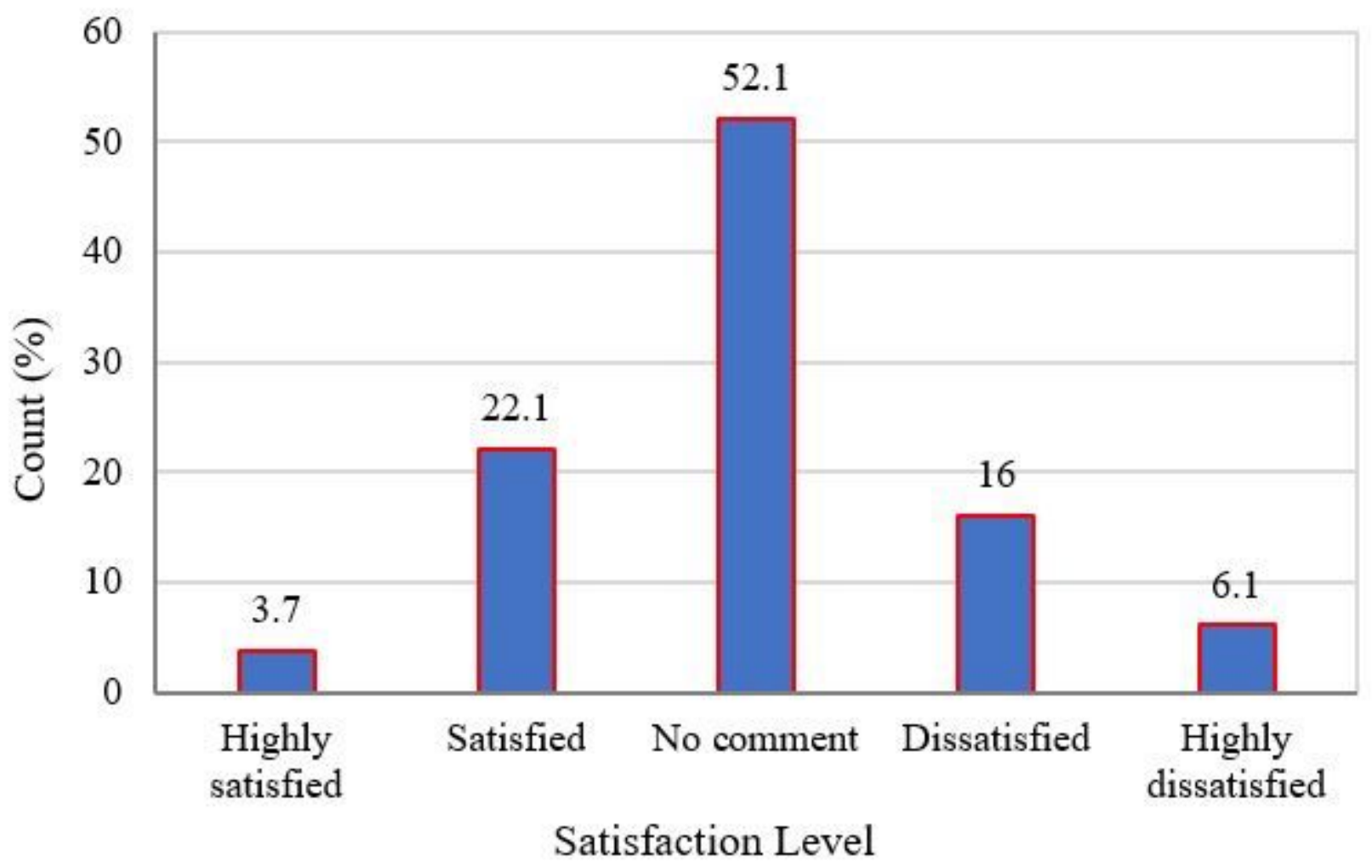

Figure 3

Relative frequency distribution concerning satisfaction with the quality of virtual education among studied students of Alborz dental school 